\title{
Integrated modelling of water delivery options for the Coorong South Lagoon
}

\author{
M. Montazeri, M.S. Gibbs, C. Bloss, D. Way and C. Wood \\ Science, Monitoring and Information Division, Department for Water, Government of South Australia
}

\begin{abstract}
The Coorong, along with the Lower Lakes and Murray Mouth is one of the largest of the internationally significant wetlands recognised under the Ramsar Convention within the Murray Darling Basin. Severe drought in the Basin over recent years has resulted in record low inflows and has had a significant impact on the ecological health of the Coorong. However, there is still further volume that flows west and out to sea through the Lower South East constructed drainage network that could potentially be diverted north and delivered to support the Coorong South Lagoon (CSL).

The Coorong South Lagoon Flow Restoration Project (CSLFRP), which is part of the South Australian Government's Murray Futures program and funded by the Australian Government's Water for the Future strategy, has to date investigated options for diverting significant volumes of water from the drainage network of the South East northwards to the Coorong using a combination of purpose-built floodways and existing flow paths. This paper presents the investigations, in particular the modelling work undertaken, and the outcomes of the CSLFRP study.
\end{abstract}

The aim of this study is to provide greater confidence in estimates of water availability from the untapped resources in the South East drainage system available, to potentially be diverted to the CSL using two main flow paths. Accurate estimation of water availability is complicated by a lack of flow gaugings, extremely flat terrain, shallow water table, and highly modified landscape in the region. To do this, a range of modelling tools and techniques were used to replicate the processes of rainfall-runoff generation, losses and conveyance of water. The key modelling processes involved were:

- Hydrologic modelling of the South East catchments to generate time-series of flows from runoff and diversions.

- Hydraulic modelling of the flow paths to provide estimates of width, depth and volume of floodways/drains and also water surface and water elevation for input to the transmission loss and water balance analysis.

- Transmission loss analysis to estimate losses to groundwater for various flow paths and flow rates.

- Water balance modelling to estimate annual yield volumes to the CSL. Diversion and runoff volumes from the hydrologic model, drain's dimensions from hydraulic model and losses to groundwater from the transmission loss model were used as inputs to the water balance models.

Based on the maximum diversion limits determined, the yield delivered to the CSL was estimated under different climate conditions. Analysis of the probability of occurrence of different yields expected for the different flow paths, which highlights the major difference between proposed flow paths, was also undertaken. Finally, the yield expected from each diversion point was calculated to illustrate what incremental flow diversion increase would be achieved by a staged approach to a potential civil works program.

Keywords: Coorong South Lagoon (CSL), Upper South East (USE), Diversion Rate, Transmission Loss 


\section{INTRODUCTION}

The Coorong, along with the Lower Lakes and Murray Mouth, is one of the largest of the internationally significant wetlands recognised under the Ramsar Convention within the Murray-Darling Basin. Historically, the hydrology of the Coorong has been influenced by significant fluctuations in seasonal discharge from the River Murray to the Lower Lakes, surface water flows from the South East of South Australia (SE), as well as local surface water and groundwater inputs.

Since European settlement, construction of the system of barrages to maintain water levels in the Lower Lakes, over allocation in the Murray-Darling Basin, construction of the extensive drainage network in the South East and changes in land use locally and particularly, severe drought in the Basin over recent years have all influenced the hydrology of the Coorong. While the North Lagoon is most affected by tidal flushing from the Murray estuary, the salinity regime in the South Lagoon may have been more strongly influenced by surface runoff from the South East. This paper provides an assessment of the additional surface runoff that may be delivered to the Coorong South lagoon (CSL) via two proposed drainage alignments. Further assessment would be required to investigate the impact that any flow delivered might have on the hydrodynamics and ecology of the CSL.

\section{COORONG SOUTH LAGOON FLOW RESTORATION PROJECT (CSLFRP)}

The Coorong South Lagoon Flow Restoration Project (CSLFRP) has to date investigated options for diverting water from the drainage network of the South East northwards to the Coorong using a combination of purpose-built floodways and existing flow paths. However, there is still further runoff that flows west and out to sea through the Lower South East constructed drainage network that could potentially be diverted north and potentially delivered to the CSL. Australian Water Environments (AWE) in this respect studied a series of delivery options and incorporated a number of climate change scenarios to provide estimates of available yield to the CSL (AWE, 2009a).

Department for Water (DFW) was also engaged to undertake a hydrological and hydro-geological investigation to provide greater confidence in estimates of available water to the CSL. Two proposed flow paths were considered, each containing four possible diversion points. For consistency with previous studies, these two paths are named flow path 02 and flow path 03 , as seen in Figure1.

\section{METHODOLOGY}

Estimation of volumes available to support the ecology of the CSL in this region is extremely complex. Firstly, runoff must be estimated from catchments that are sparsely gauged. Secondly, the losses involved in the transmission of this runoff, along up to $160 \mathrm{~km}$ of open channel drains, must be estimated, based on the water level in the drain, the level of groundwater near each drain, and the soil properties involved. A range of modelling tools and techniques were used to replicate the processes of rainfall-runoff generation, losses and conveyance of water.

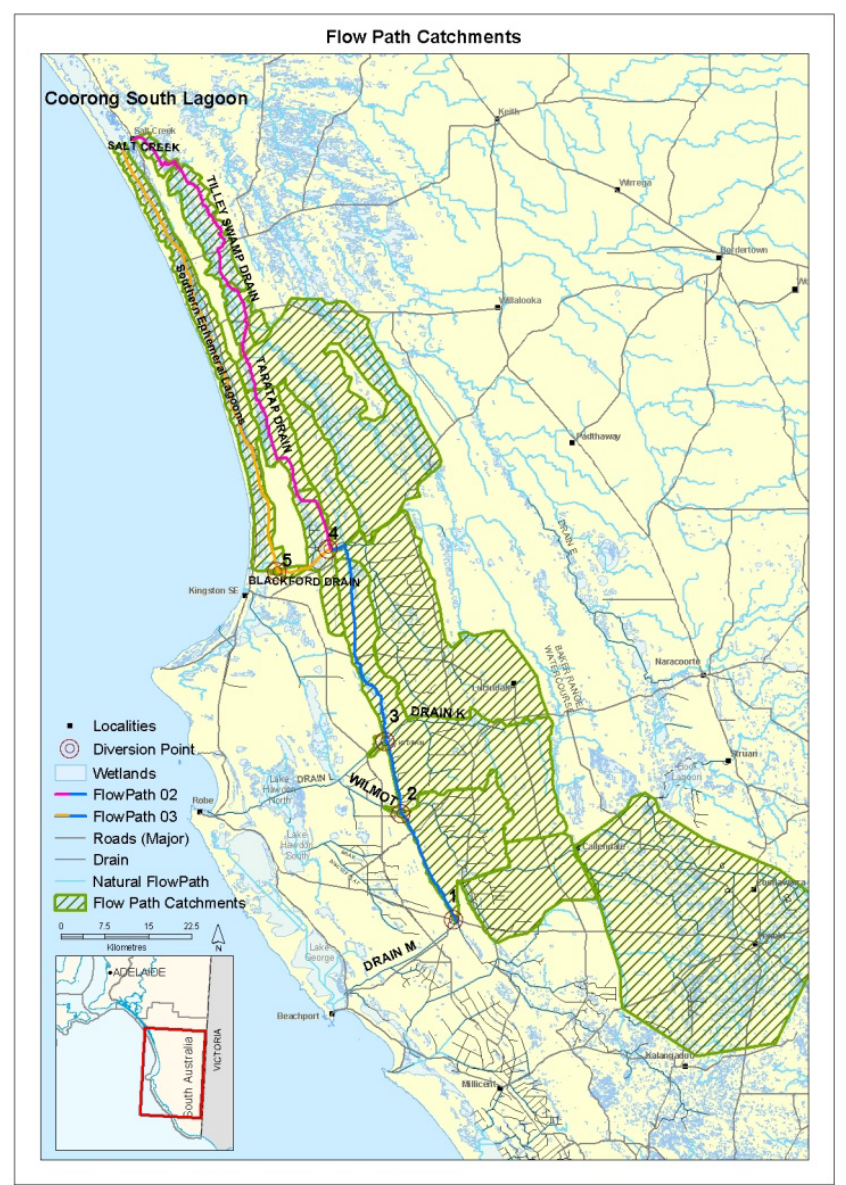

Figure 1 Study Area 


\subsection{Hydrological Modelling}

\section{Runoff Estimation}

In the first stage of modelling, the runoff expected from contributing catchments was estimated by extension and refinement of daily rainfall runoff models as described by Wood and Way (2010). The commonly used AWBM model structure was adopted, within the WaterCRESS platform (Cresswell 2002). For the historic climate conditions, the rainfall and evaporation inputs required for the rainfall runoff model were derived from the SILO Patched Point Datasets (Jeffrey et al. 2001). To consider possible changes in a future climate, the projections adopted by AWE (2009a) for 2030 conditions have been used in this work. The study period was chosen as a standard 30-year period of 1971-2000 for a number of reasons especially because it is sufficiently long to capture both wet and dry periods and also excludes the effects of the drought over the last decade (Wood and Way, 2010).

\section{Minimum and Maximum Diversion Rates}

Four diversion points at the intersection of existing East-West drains and the proposed flow paths were identified to divert available water northward to the CSL, rather than directly out to the Southern ocean. The maximum diversion rates are dependent on the capacity of the receiving flow path, and have been subject to an optimisation study. Hence, optimum maximum diversion rates were estimated to identify the point at which the benefit of increasing the diversion capacity is significantly reduced. The minimum diversion thresholds were determined based on the requirements of the receiving environment downstream of the diversion point. In this study the same minimum diversion thresholds as those determined by AWE (2009a) have been applied.

Table 1 Maximum and Minimum diversion rates

\begin{tabular}{|l|l|l|l|}
\hline Node & Location & $\begin{array}{l}\text { Minimum diversion rate } \\
\text { (AWE, 2009a) }\end{array}$ & $\begin{array}{l}\text { Maximum Diversion rate } \\
\text { (Optimization Study) }\end{array}$ \\
\hline 1 & intersection of Drain M and both Flow Paths & $\begin{array}{l}\text { All flows below maximum } \\
\text { diversion rate once 30 GL } \\
\text { passed in a calendar year }\end{array}$ & 250 ML/day \\
\hline 2 & intersection of Wilmot Drain and both Flow Paths & $22 \mathrm{ML} /$ day & $500 \mathrm{ML} /$ day \\
\hline 3 & intersection of Drain K and both Flow Paths & $10 \mathrm{ML} /$ day & $250 \mathrm{ML} /$ day \\
\hline 4 & intersection of Blackford Drain and Flow Path 02 & $0 \mathrm{ML} /$ day & $1000 \mathrm{ML} /$ day \\
\hline 5 & intersection of Blackford Drain and Flow Path 03 & $0 \mathrm{ML} /$ day & $1000 \mathrm{ML} /$ day \\
\hline
\end{tabular}

\subsection{Hydraulic Modelling}

In order to estimate the losses along the transmission channel, the head difference, and hence water level in the drain, is required. To estimate this, hydraulic modelling was undertaken using HEC-RAS in its steadystate mode, with its companion tool HEC-GeoRAS to extract flow paths and cross-sections in GIS. Models were developed for all reaches of each flow paths to provide meaningful inputs to the transmission loss and water balance analysis, where a reach was defined by the presence of a diversion point or a controlling sill along discrete lagoons. Data used to develop the hydraulic models included the 2 meter digital elevation model (DEM) of the South East, construction plans for existing drains and conceptual channel profiles provided in KBR's (2009) final report. Manning's roughness values were selected based on aerial photographs. A range of flow rates were assessed in each reach and corresponding outputs such as width and depth of channel, surface area of contained water and longitudinal profile of water surface elevation prepared as a lookup table to be used in transmission loss analysis and water balance model.

\subsection{Transmission Loss Analysis}

Morgan et al. (2011) outlined a methodology for estimation of seepage losses from proposed flow paths as part of this study. They proposed three alternative cases to quantify stream losses to groundwater system based on the potential physical conditions observed in the field. All three methods are simple analytical 
mathematical models, for one-dimensional flow under steady state conditions, and assume the flow medium (soil/aquifer) is homogeneous and isotropic.

For each reach, plots were made showing the elevation of the water level in the proposed drain derived from hydraulic models (based on a particular flow scenario), the bottom elevation of the drain, the elevation of the groundwater table in spring when it is expected to be highest and flow is expected in the drain, and the bottom of the soil profile underlying the surface. For the majority of

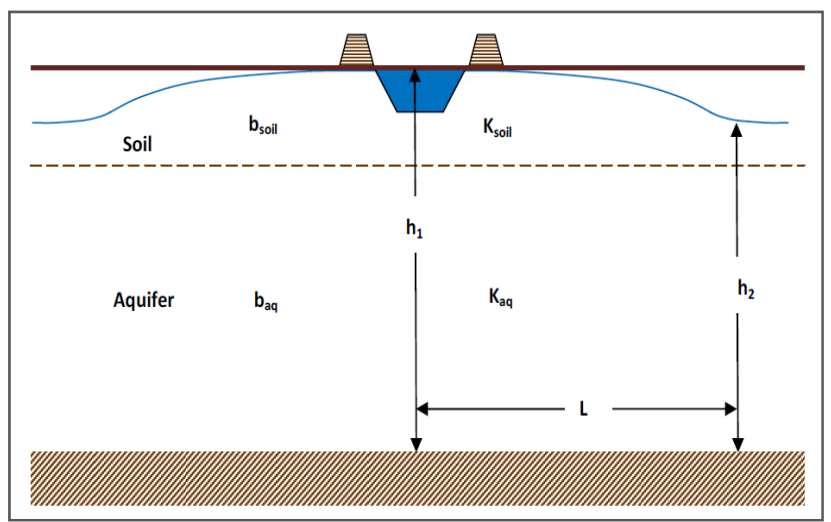

Figure 2 Case 2. Saturated flow: The channel sits within the soil layer and the watertable is in the soil layer reaches, case 2 from Morgan, Green and Wood (2011) was identified as the most appropriate scenario (Figure 2). In this case, both the channel and the groundwater table sit within a low conductivity soil layer above the regional aquifer. At least $0.5 \mathrm{~m}$ of soil is present between the bottom of the channel and the top of the aquifer.

For each modelled reach, seepage for this case was calculated as:

$$
\mathrm{Q}=\mathrm{K}_{\mathrm{ave}} \frac{\mathrm{h}_{1}{ }^{2}-\mathrm{h}_{2}{ }^{2}}{\mathrm{~L}}
$$

Where $\mathrm{Q}$ is the seepage per metre of channel; $\mathrm{K}_{\mathrm{ave}}$ is the average weighted hydraulic conductivity of the soil and aquifer; $h_{1}$ is the elevation of water in the channel (derived from Hydraulic analysis for particular flow rate); $h_{2}$ is the elevation of the watertable (Spring Water table); $\mathrm{L}$ is the distance from the channel that $\mathrm{h} 2$ is measured. In line with the assumptions used by AWE (2009a), as well as the spatial analysis performed in GIS, L was set at $250 \mathrm{~m}$ in all cases.

The average hydraulic conductivity, $\mathrm{K}_{\mathrm{ave}}$, in a saturated, two-layer system, was calculated according to Equation 2 (Brunner et al., 2009):

$$
\mathrm{K}_{\mathrm{ave}}=\left[\frac{1}{\mathrm{~b}_{\text {soil }}+\mathrm{b}_{\mathrm{aq}}} \times\left(\frac{\mathrm{b}_{\text {soil }}}{\mathrm{K}_{\text {soil }}}+\frac{\mathrm{b}_{\mathrm{aq}}}{\mathrm{K}_{\mathrm{aq}}}\right)\right]^{-1},
$$

Where $\mathrm{K}_{\mathrm{ave}}$ is the average weighted hydraulic conductivity of the soil and aquifer; $\mathrm{b}_{\text {soil }}$ is the thickness of the soil layer (m); $b_{a q}$ is the thickness of the aquifer (m); $K_{\text {soil }}$ is the hydraulic conductivity of the soil $(\mathrm{m} / \mathrm{d}) ; \mathrm{K}_{\mathrm{aq}}$ is the hydraulic conductivity of the aquifer $(\mathrm{m} / \mathrm{d})$.

A spreadsheet was populated with all the data necessary to calculate Equation 1 and Equation 2 for each reach, and transmission loss calculated. To incorporate transmission losses in water balance model, different range of flow rates were assessed in each reach and corresponding transmission loss prepared as a lookup table.

\subsection{Water Balance Modelling}

Water balance analyses were conducted in a spreadsheet format on a daily time step. The following approach used to compute the daily water balance for each reach separately:

- Inflow is calculated based on the outflow from an upstream reach, from a diversion node, and/or from any contributing catchments.

- The corresponding water level to incoming flow is determined based lookup tables derived from hydraulic analysis.

- The change in volume from water body based on the difference between any rainfall input and evaporation output is then calculated.

- Groundwater losses are then applied based on lookup tables derived from Transmission analysis.

- Outflow then is calculated in each reach as the sum of the inflow to the reach plus the losses and gains. 


\section{DISCUSSION AND RESULTS}

\subsection{Annual Median and Average Yield to the CSL}

The yield to the CSL was calculated using a daily time step water balance model for different climate conditions. The most significant factor for the difference between flow path 02 and flow path 03 is the contribution of the local catchments from the east to the Taratap and Tilley Swamp drain at very end of flow path 02 which although it does not contribute to flow path 03 itself but it contributes to CSL through existing drainage network. Hence, to provide a fair comparison of both flow paths, yield from these catchments is included to the yield of flow path 03 . Based on this comparison, the results indicate that slightly larger average and median annual volumes are delivered to the CSL by flow path 02, as this path has lesser losses and smaller storages to fill and spill, in comparison to flow path 03

The impacts of the climate change scenarios were also modelled, where the projected reduction in rainfall can be seen to significantly reduce the yield. A 2030 climate change median scenario (CCM) reduces the median annual volumes delivered to the CSL for flow path 02 and flow path 03 in the order of 36 and $72 \%$ respectively, while the climate change dry (CCD) reduces volumes to the CSL for flow path 02 and flow path 03 by 56 and $100 \%$ respectively. This larger reduction in the yield delivered to the CSL for flow path 03 is due to the larger storages involved in this path, where smaller annual flows do not fill the wetlands along the path that must fill and spill before water is delivered to the terminal CSL.

Table 2 Average and median annual volume from proposed flow paths

\begin{tabular}{|l|c|c|c|c|c|c|}
\hline & \multicolumn{3}{|c|}{ Median Annual, GL } & \multicolumn{3}{c|}{ Average Annual, GL } \\
\hline Climate Scenario & Historic & CCM & CCD & Historic & CCM & CCD \\
\hline Flow Path 02 & 54.59 & 34.94 & 23.85 & 49.40 & 35.05 & 23.98 \\
\hline Flow Path 03 & 13.69 & 3.85 & 0.00 & 17.73 & 9.22 & 3.95 \\
(Existing network) & 26.93 & 19.59 & 14.62 & 26.21 & 19.56 & 14.06 \\
Total & 40.62 & 23.43 & 14.62 & 43.94 & 28.78 & 18.01 \\
\hline
\end{tabular}

\subsection{Yield Probability of Occurrence}

The annual exceedence probabilities were computed for each scenario to highlight the annual variability in the expected yield from each flow path. Figure 3 can be interpreted as $80 \%$ of the years will produce flow of $11 \mathrm{GL}$ to be diverted to the CSL under historic climate condition. Flow path 02 can be seen to be relatively reliable, with four in five years on average delivering some flow to the CSL, and a relatively linear increase in the flow diverted with the probability of occurrence, up to $104 \mathrm{GL}$ for a one in ten year event.

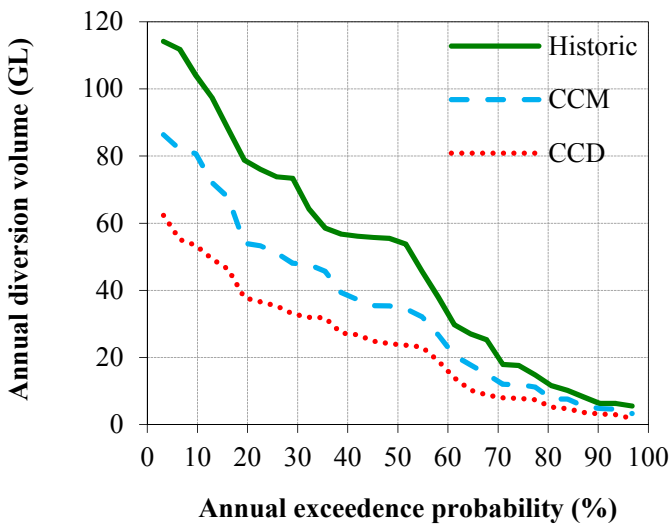

Figure 3 Annual exceedence probability of annual volume at CSL from flow path 02

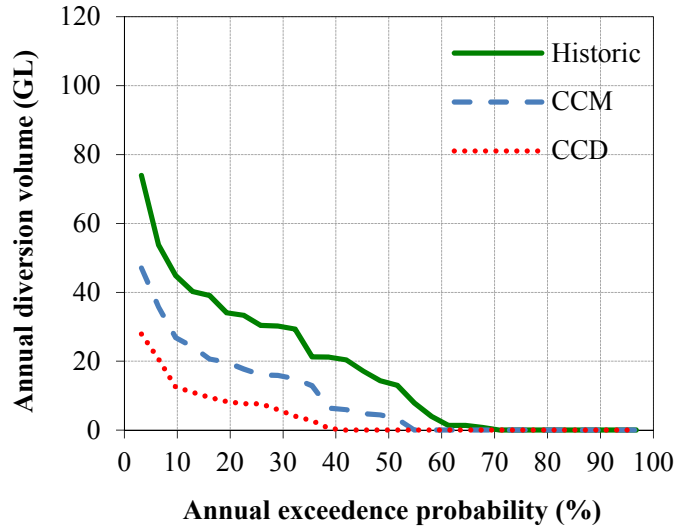

Figure 4 Annual exceedence probability of annual volume at CSL from flow path 03 
As presented in Figure 4, flow path 03 is expected to deliver less total volume for events with the same probability of occurrence, when compared to flow path 02 . The reliability of flows from this path is also reduced, with some flow expected $60 \%$ of the time under historic conditions, reducing to $52 \%$ and only $40 \%$ for the median and dry climate change scenarios respectively.

The volumes of water delivered to the CSL were found to be highly variable from one year to the next. For instance, under historic climate condition along flow path 02, annual flows varied between 5.5 GL and $110 \mathrm{GL}$, with volumes greater than $79 \mathrm{GL}$ occurring two out of ten years on average. Similarly, for flow path 03 the annual flows varied between $0 \mathrm{ML}$ and $74 \mathrm{GL}$ with two out of ten years expecting a yield of greater than $34 \mathrm{GL}$. When the total volume delivered to the CSL is considered (i.e. including the contribution of the existing drainage network for flow path 03), there is little difference between the total yields delivered to the CSL between two flow paths on average, with $49 \mathrm{GL}$ expected from flow path 02, compared to $44 \mathrm{GL}$ from flow path 03 . However, flow path 02 is more reliable, with some yield expected from this path for historic climate conditions in all years, compared to $70 \%$ from flow path 03 and the reliability of flow path 03 also reduces much quicker for the climate change scenarios. Hence, when the variability of flows is considered, flow path 02 will provide the highest volume to restore flows to the CSL.

\subsection{Staged Delivery of Yield}

To provide an insight into the benefit of extending the flow restoration project to intercept flows from the diversion points further and further upstream, total yield to the CSL were broken down to indicate the cumulative effect of each diversion point. Again, the yield from existing drainage network is included for both flow paths for fair comparison.

Table 3 Staged delivery volume delivered to CSL—historic climate condition

\begin{tabular}{|l|c|c|c|c|}
\hline \multirow{2}{*}{ Diversions } & \multicolumn{2}{|c|}{ Flow Path 02 } & \multicolumn{2}{c|}{ Flow Path 03 } \\
\cline { 2 - 5 } & Median & Mean & Median & Mean \\
\hline Existing drainage network (EDN) & 26.93 & 26.21 & 26.93 & 26.21 \\
\hline $\mathrm{EDN}+\mathrm{BF}_{\text {(Point 4 or 5) }}$ & 43.67 & 40.54 & 34.23 & 35.28 \\
\hline $\mathrm{EDN}+\mathrm{BF}_{\text {(Point 4 or 5) }}+\mathrm{K}_{(\text {(Point3) }}$ & 49.45 & 44.78 & 37.43 & 39.41 \\
\hline $\mathrm{EDN}+\mathrm{BF}_{\text {(Point 4 or 5) }}+\mathrm{K}_{\text {(Point3) }}+\mathrm{W}_{\text {(Point2) }}$ & 54.46 & 48.29 & 40.22 & 42.86 \\
\hline $\mathrm{EDN}+\mathrm{BF}_{\text {(Point 4 or 5) }}+\mathrm{K}_{\text {(Point3) }}+\mathrm{W}_{\text {(Point2) }}+\mathrm{M}_{\text {(Point1) }}$ & 54.59 & 49.40 & 40.62 & 43.94 \\
\hline
\end{tabular}

The benefits of combining the existing volume with that from diversion on Blackford drain can be seen from "EDN + BF" for each flow path under historic climate condition. In average, an extra 10 GL/year is expected to be provided to the CSL via flow path 02 from just catchments contributing to Blackford drain (as the difference between the EDN and EDN + BF). Similarly, the benefit gained by extending the route to intercept drain $\mathrm{K}$ can be seen as "EDN $+\mathrm{BF}+\mathrm{K}$ " and again to Wilmot drain "EDN $+\mathrm{BF}+\mathrm{K}+\mathrm{W}$ " where the combination of drain $\mathrm{K}$ and Wilmot drain provides a similar yield to the CSL as that obtained from the Blackford drain local catchments. Finally, the benefit by completing the route to intercept drain $\mathrm{M}$ can be seen to be extremely limited "EDN $+\mathrm{BF}+\mathrm{K}+\mathrm{W}+\mathrm{M}$ " with an average of 1 GL gained from drain $\mathrm{M}$ in wet years only since the median is zero in both flow paths.

\subsection{Uncertainty of groundwater loss analysis}

The potential groundwater losses involved in the drainage network and lagoons provides the largest source of uncertainty in the estimated yields presented in this study. Also, these losses are the most likely to influence the most suitable flow path to be adopted to restore flows to the CSL. For example, in this study it has been assumed that there is a certain volume that will be sustained in each lagoons located at very end of flow path 03 and the groundwater level will be high enough to make any losses to groundwater negligible. If this is not the case, and the lagoons are a losing system, the yield expected from flow path 03 will be significantly 
reduced, and no longer comparable to flow path 02 . However, there is also the possibility that the lagoons and surrounding drainage network are a gaining system, increasing the yield expected from this flow path. Hence, determination of aquifer properties (conductivity and thickness) in the area of interest would greatly improve estimates. This would likely require the drilling of new observation wells to perform aquifer tests.

\section{CONCLUSION}

This study investigated water availability to be delivered from the South East drainage system to the CSL, to assess the feasibility of implementing such a system. A combination of modelling approaches, including daily time-step hydrological modelling, hydraulic modelling, analytical groundwater models and a water balance model were required to provide valuable estimates of the yields available to be diverted from the South East region to the CSL. The total volume delivered to the CSL is not the only consideration in the decision to implement a capital works program, for example the degree of engineering works required to provide the necessary drain capacity, the ecological benefits provided to the ephemeral lagoons associated with flow path 03, and the trade of between diverting water to the CSL or using water for environmental purposes more locally in the South East. The distribution of yields estimated by this study provide valuable input to future stages in the decision making process on the feasibility of constructing further drains to support the ecology of the CSL.

\section{ACKNOWLEDGMENTS}

Further details of these results can be found in Montazeri et al. (2011). The authors acknowledge the invaluable inputs of Geoffrey Wood, Hydrologist and Dr Graham Green, Senior Hydrogeologist.

\section{REFERENCES}

Australian Water Environments (AWE) 2009a, Coorong South Lagoon restoration project-hydrological investigation final report June 2009, prepared by Australian Water Environments Pty Ltd for Department of Water, Land and Biodiversity Conservation, Adelaide

Brunner, P., Cook, P.G. and Simmons. C.T. 2009, Hydrogeologic controls on disconnection between surface water and groundwater, Water Resources Research, 45, W01422, doi: 10.1029/2008WR006953

Cresswell, D.J. 2002, WaterCRESS; Water Community Resource Evaluation and Simulation System, Reference manual, Department of Water, Land and Biodiversity Conservation, Adelaide

Jeffrey, S.J., Carter, J.O., Moodie, K.M. and Beswick, A.R. 2001, Using spatial interpolation to construct a comprehensive archive of Australian climate data in Environmental Modelling and Software, Vol .16/4, pp. $309-330$

Kellogg Brown \& Root Pty Ltd (KBR) 2009, Coorong South Lagoon flow restoration project—engineering feasibility study, Final report

Montazeri M, Way D, Gibbs M, Bloss C \& Wood C. 2011, Coorong South Lagoon Flow Restoration Project - Hydrological modelling and transmission loss analysis, DFW Technical Note 2011/05, Department for Water, Adelaide

Morgan, L., Green, G. and Wood, C. 2011, Simple analytical methods for estimating channel seepage from constructed channels in the Upper South East of South Australia, Technical Note 2011/04, Department for Water, Adelaide

Wood, G. Way, D. 2010, Development of the technical basis for a regional flow management strategy for the South East of South Australia, Technical Report 2010/12, Department for Water, Adelaide

Way, D. Heneker, T.M. 2007, Preliminary hydrological investigations for the diversion of flow from the South East to the Coorong South Lagoon, Technical Note 2007/06, Department of Water, Land and Biodiversity Conservation, Adelaide 